\title{
Social Media Etiquette for the Modern Medical Student: A Narrative Review
}

\author{
Brittany Harrison, ${ }^{1}$ Jeewanjit Gill, ${ }^{1}$ Alireza Jalali. ${ }^{2}$
}

\begin{abstract}
Most medical students worldwide are using some form of social media platform to supplement their learning via file sharing and to stay up-to-date on medical events. Often, social media may blur the line between socialization and educational use, so it is important to be aware of how one is utilizing social media and how to remain professional. Research has yielded some troublesome themes of misconduct: drunken behaviour, violations of confidentiality and defamation of institutions. Because there is no universal policy to monitor online professionalism, there exists the potential for indiscretions to occur. It has been reported that misdemeanours can affect future residency placements and employment for medical students. Accordingly, studies suggest that educators need to recognize this new era of professionalism and adapt policies and reprimands to meet modern outlets where professionalism may be violated.
\end{abstract}

Keywords: Social media, Medical Students, Internship and Residency, Medical Education, Continuing Medical Education (Source: MeSH, NLM).

\section{Introduction}

It has been observed that the majority of North American and European medical students use various social media platforms (Facebook $®$, Twitter $®$, YouTube ${ }^{\circledR}$ ) for file sharing, circulation of educational resources and staying connected with peers. ${ }^{1-3}$ Defining online professionalism is difficult, and there are a number of cases where lapses occur in the medical student population. Almost all medical schools in North America and Europe have an online presence, yet rarely are there guidelines or rules that punish unprofessional behaviour. Research shows that there is a potentially dangerous dichotomy between the online social lives of modern medical students and profesAbout the author: Brittany sionalism requirements of medical career for which they are Harrison is in her third training.4-6 Though this is a problem in professional medical year of medical school at practice as well, this narrative review will focus on examining the University of Ottawa, social media use by medical students, with a concentration canada. She recently presented at the Canadian Conference for Medical Education on the topic of social media professionalism. on online professionalism and how education on the topic is, or should be, integrated into the world-wide medical school curricula. Twenty first century medical students ought to take care in using social media in the most effective way possible.

\section{Search Strategy and Selection Criteria}

A literature search was conducted using Coogle Scholar, PubMed (Medline), and ScOPUS. Key word combinations included "medical student professionalism and social media", "medical education and social networking", and "undergraduate + medical school education + social media". The 283 results acquired were then limited by year of publication; only articles published after 2007 were included in order to stay as current as possible. Twenty-two articles were chosen for analysis. The inclusion criteria incorporated articles on medical student-spe- cific social media use. Articles pertaining to practicing physicians were excluded from the review. Emerging themes were assembled into this narrative review. This review follows the Preferred Reporting Items for Systematic Reviews and Meta-Analyses (PRISMA) Statement.?

\section{Major Trends}

The use of social media is common and growing in the medical profession, as more individuals obtain the technology and know-how to use these new platforms. ${ }^{2-3}$ In a survey of 132 U.S. medical schools, 95\% had Facebook $®$ presence, and $25 \%$ had school-specific pages, while $10 \%$ had Twitter $®$ accounts. ${ }^{2}$ These numbers are comparable with those in Canadian and European literature; thus, most medical students in North America and Europe have some online presence.' Professionalism is a longstanding foundation of the medical profession, and as online presence becomes more common, perceptions of professional behaviour must evolve.

Social media has become an advantageous platform for a number of reasons. Students use social media to gain and share information, to communicate and discuss within study groups, and to motivate each other to generate discussion and share thoughts. ${ }^{8}$ In addition, interaction with tutors can be easily facilitated via online platforms. ${ }^{8-10}$ Facebook ${ }^{\circledR}$ and Twitter ${ }^{\circledR}$ may provide an opportunity for creativity, engaging students in educational settings beyond the scope of traditional medical education. ${ }^{8}$ Also, Twitter ${ }^{\circledR}$ allows for quick contact with noteworthy physicians and scientists who would otherwise be difficult to reach.

${ }^{1}$ Medical Student, University of Ottawa, Canada.

${ }^{2}$ Distinguished professor, Faculty of Medicine, University of Ottawa, Canada. 
In addition to the increase in overall social media usage in the medical student population, it has been found that there are trends of usage across the span of the medical undergraduate program. Social media usage declines as medical students reach the end of their medical degree. ${ }^{12}$ Thus, approaches to "technology-enhanced education" might need to be tailored differently for clinical versus pre-clinical students; pre-clinical students used more social forums, while clinical students used social media for obtaining information. ${ }^{13}$ The above paragraphs note broad themes of social media usage in the medical student population.

\section{Atmosphere of Misuse}

Medical professionals are increasingly participating in online social media, and evidence is emerging from studies, legal cases and media reports that its use can pose a risk in the medical community. ${ }^{14}$ Information stored online is easily accessible and often permanent, so students ought to consider the virtual reach of their posts and comments. ${ }^{3}$ Because of its multiple uses, social media may blur the line between socializing and studying/work. ${ }^{5}$ Current medical students have grown up in a world where information is shared liberally, and social media is a part of everyday life. Many do not see social media as part of their professional identity, and it is difficult to differentiate between public and private content. It is for this reason that lapses in professionalism occur. ${ }^{5.10}$

Defining e-professionalism is difficult, but the most accepted definition is this: "the attitudes and behaviours reflecting traditional professionalism paradigms but manifested through digital media". ${ }^{5}$ In a 2009 study published in Journal of the American Medical Association, 47/78 (60\%) of medical schools had had at least one case of unprofessional posting by one or more of their medical students. ${ }^{15}$ At one U.K. medical school, $54 \%$ of students have seen unprofessional behaviour by their colleagues, most of which involve discussion of clinical encounters. Although there is no governing policy blanketing these issues, unprofessionalism can result in punishments as severe as expulsion from school. ${ }^{2}$

\section{Types of Inappropriate Behaviour}

With every post on any social media site, the user creates a permanent and far-reaching digital footprint. ${ }^{15}$ Across the literature, there are five common categories of inappropriate posting by medical students:

- Drunken behaviour; ;,5

- Overt sexually related content, ${ }^{2,5}$

- Foul language/derogatory humour; ;, 2, 12

- Breaches in patient confidentiality; 2,3,5,15

- Defamation: activities that damage the reputation of an organization or individual. ${ }^{3}$

One study evaluated the Twitter ${ }^{\circledR}$ and Facebook ${ }^{\circledR}$ profiles of 501 medical students. It was found that some Facebook ${ }^{\circledR}$ groups that these students joined were vulgar in nature, and it was noted that $70 \%$ of these students' profiles displayed drunkenness and foul language. ${ }^{12}$ Some students seem to think social media is for venting, whereas older generations believe that this type of posting is inappropriate.

of particular interest are the patient confidentiality concerns that come up in the literature. According to Belean et. al., 30\% of professional violations were linked to patient confidentiality. ${ }^{11}$ One issue is the ubiquity of photographic devices, which pose a significant risk to clinical patients as well as standardized patients used in training. The absence of strong online professionalism tenets manifests itself, in one case, in the form of unauthorized recordings during demonstrations of pelvic exams. ${ }^{15}$ The Australian Medical Association warns that the "anonymity potentially afforded online is no excuse for unprofessional behaviour". ${ }^{14}$

\section{Professionalism Online}

Almost all medical schools have a social media presence, but most have no method of addressing unprofessional behaviour, ${ }^{2,17}$ nor do they have a set of solid rules pertaining to unprofessional postings. ${ }^{16,17}$ With new technologies being integrated into the lives of medical students, there should be instruction on online professional behaviour to give students recommendations on how they ought to conduct themselves. In this area, there is significant room for improvement. ${ }^{2,7,19,20}$

Professionalism is a core pillar of most medical school curricula across the world; however, it is often unclear how e-professionalism is integrated into the teachings on this topic. ${ }^{17}$ In a study of 130 U.S. medical schools, only $38 \%$ had policies on online student postings, but they were vaguely written and only $10 \%$ had policies explicitly mentioning social media or online social networking. ${ }^{2}$ The challenges are the lack of systems for identifying, tracking and remediating professionalism lapses and the difficulty of anticipating new technological advances. ${ }^{19}$

In 2013, the Canadian Federation of Medical Students (CFMS) published guidelines on social media professionalism. Their goal was to have medical students, as proto-professionals, act in a way that they would feel comfortable observing their own physicians acting away from clinical duties..$^{20}$ The publication is divided into four sections:

1. Clear guidelines regarding professional boundaries online.

2. Suggestions for how medical students can present themselves in the best possible light.

3. Case samples with explanation and critique.

4. A survey of the literature on the topic of social media professionalism.

This set of guidelines will be updated as social media progresses and new platforms are created. ${ }^{20}$ Documents such as this one are important for medical schools to add to their professionalism teaching, as social media is now a major aspect of the public presence of medical professionals.

\section{Consequences on Future Career}

owing to the permanence and worldwide reach of online posting, there are risks inherent in placing any content online. One of the more detrimental issues is that social media misconduct may affect placements in residency programs. Medical students may not associate their lack of professionalism with their current clinical or future career placements, for they may not understand how their opinions could be misinterpreted. ${ }^{12}$ However, studies have exhibited that online indiscretions can 
affect one's own future employment, that such indiscretions can compromise the public's perception of the medical field, ${ }^{10,15}$ and indeed that online misconduct can translate into shaming the entire profession. ${ }^{15,16,21}$ The trend is that employers are increasingly screening potential employees online; between one-fifth and two-thirds of employers conduct internet searches, including social networking sites. ${ }^{14}$ The public now has online access to information about their physicians. Information on the Internet is permanent and can stay with a student until he or she is a qualified physician; for this reason, medical students should be prudent now about their posts."

\section{How to Educate}

It is clear that there are too few medical school policies on social media conduct. Most agree that instruction in professionalism needs to be addressed for the 21st-century medical student and this should begin at medical school matriculation..$^{5,16,22}$

A few institutions have given advice on how best to address this shortfall. Not only will policies deter students from unprofessional behaviour, 15,23 but it has been suggested that it is the responsibility of medical educators to recognize the online environment that students are in and to tailor their professionalism courses to include this setting. ${ }^{17,23}$ In addition, it has been recommended that engaging various users is the best way to create guidelines. ${ }^{16,17}$ In addition, e-learning and social media sessions, ${ }^{9}$ as well as facilitated group discussion followed by individual reflection, ${ }^{11,22}$ should be incorporated into medical learning. Finally, because residents are generally closer in age to medical students, studies suggest they would be the best people to mentor students on the implications of online unprofessionalism. ${ }^{17,24}$ Taken together, these measures may help students understand that they ought to be cautious about what they post online. The CFMS' new guidelines are attempting to control online professionalism issues in Canadian medical institutions; a number of medical schools around the world are joining in and integrating these teachings into their curricula.

\section{Conclusion}

Social media and social networking platforms are becoming a ubiquitous source of information sharing in the realm of medicine. Medical students from Canada, and around the world, are engaged in this technology. Because of the permanence and reach of the Internet, it is important that caution is taken to ensure that lapses in professionalism do not occur, since these can affect residency and employment. In addition to the issue of future employment, students should, of course, avoid misconduct because it can shame both the profession for which they are training and the institution that they are attending. A number of suggestions have been made for integrating e-professionalism into medical education. Policy and research into the creation of guidelines will help to ensure that the integrity of the medical profession is not compromised.

\section{References}

1. Garner J, O'Sullivan H. Facebook and the professional behaviours of undergraduate medical students. Clin Teach. 2010 Jun;7(2):112-5.

2. Kind T, Genrich G, Sodhi A, Chretien K. Social media policies at US medical schools. Med Educ Online. 2010 Sep 15;15

3. Mansfield S, Morrion S, Stephens H, Bonning M, Wang S, Withers J. Social media and the medical profession. Med J Australia. 2011 Jun 20;194(12):642-4. 4. Chretien K, Kind T. Social media and clinical care: Ethical, professional and social implications. Circulation. 2013 Apr 2;127(13):1413-21.

5. Kaczmarczyk JM, Chuang A, Dugoff L, Abbott JF, Cullimore AJ, Dalrymple J, et al. e-Professionalism: A new frontier in medical education. Teach Learn Med. 2013;25(2):165-70.

6. Ross S, Lai K, Walton JM, Kirwan P, White JS. "I have the right to a private life": Medical students' views about professionalism in a digital world. Med Teach. 2013 Oct; 35(10);826-31.

7. Liberati A, Altman DG, Tetzlaff J, Mulrow C, G $\phi$ tzsche PC, Loannidis JP, et al. The PRISMA statement for reporting systematic reviews and meta-analyses of studies that evaluate health care interventions: explanation and elaboration. PLOS Med. 2009 Jul 21;6(7).

8. Boulos M, Wheeler S. The emerging Web 2.0 social software: An enabling suite of sociable technologies in health and health care education. Health Info Libr J. 2007 Mar;24(1):2-23.

9. Hollinderbaumer A, Hartz T, Uckert F. Education 2.0-how have social media and web 2.0 been integrated into medical education? A systematical review. GMS Z Med Ausbild. 2013;30(1):Doc14.

10. Belean G, Truong J. Social media and medical students. Med Stud J Aust. 2011 Jun;3(1):21-3.

11. Lie D, Trial J, Schaff P, Wallace R, Elliot D. "Being the best we can be": Medical students' reflections on physician responsibility in the social media era. Acad Med. 2013 Feb;88(2):240-5.

12. Thompson L, Dawson K, Ferdig R, Black EW, Boyer J, Coutts J, et al. The intersection of online social networking with medical professionalism. J Gen Intern Med. 2008 Dec;23(12):954-7.

13. Kennedy G, Gray K, Tse J. "Net Generation" medical students: Technological experiences of pre-clinical and clinical students. Med Teach. 2008 Feb;30(1):10-6.

14. Australian Medical Association Council of Doctors-in-Training, New Zealand Medical Association Doctors-in-Training Council, New Zealand Medical Students' Association, Australian Medical Students' Association. Social Media and the Medical Profession: A guide to online professionalism for medical practitioners and medical students. Australian Medical Association and New Zealand Medical Association. 2014;1-14

15. Chretien K, Greysen SR, Chretien JP, Kind T. Online posting of unprofessional content by medical students. JAMA. 2009 Sep 23;302(12):1309-15.

16. Greysen R, Kind T, Chretien KC. Online professionalism and the mirror of social media. J Gen Intern Med. 2010 Nov;25(11):1227-9.

17. Patel P, Roberts JL, Miller K, Ziegler C, Ostapchuck M. The responsible use of online social networking: who should mentor medical students. Teach Learn Med. 2012;24(4):348-54.

18. Ponce B, Determann JR, Boohaker HA, Sheppard E, McGwin G, Theiss S. Social networking profiles and professionalism issues in residency applicants: An original study-cohort study. J Surg Edu. 2013 Jul-Aug;70(4):502-7.

19. Spector N, Matz PS, Levine LJ, Gargiulo KA, MCDonald MB, McGregor RS. e-Professionalism: Challenges in the age of information. J Pediatr. 2010 Mar;156(3):345-46.

20. Brasg I. Canadian Federation of Medical Students: CFMS Guide to Medical Professionalism: Recommendations for Social Media. Executive Summary. 2013;1-31.

21. Jain S. Practicing medicine in the age of Facebook. New Engl J Med. 2009 Aug 13;361(7):649-51.

22. Cheston C, Flickinger T, Chisolm M. Social media use in medical educa- 


\section{Review}

tion: A systematic review. Acad Med. 2013 Jun;88(6):1-9.

23. MacDonald J, Sohn S, Ellis P. Privacy, professionalism and Facebook: a dilemma for young doctors. Med Educ. 2010 Aug;44(8):805-13.

24. Strausburg M, Djuricich A, Carlos G, Bosslet $G$. The influence of the residency application process on the online social networking behaviour of medical students: A single institutional study. Acad Med. 2013 Nov;88(11):17071712.

25. Gray K, Annabell L, Kennedy G. Medical students' use of Facebook to support learning: Insights from four case studies. Med Teach. 2010;32(1), 971-6.

\section{Acknowledgments}

We would like to acknowledge the University of Ottawa Undergraduate Medical Education summer project program for their support in this research.

\section{Conflict of Interest Statement at Funding}

The authors have no funding, financial relationships or conflicts of interest to disclose.

\section{Author Contributions}

Conception and design the work/idea: $\mathrm{BH} \mathrm{AJ} \mathrm{JG.} \mathrm{Collect} \mathrm{data/obtaining} \mathrm{results:} \mathrm{BH}$. Analysis and interpretation of data: $\mathrm{BH}$ AJ JG. Write the manuscript: BH. Critical revision of the manuscript: BH AJ JG. Approval of the final version: BH AJ JG. Obtaining financing: AJ.

Cite as:

Harrison B, Gill J, Jalali A. Social Media Etiquette for the Modern Medical Student: A Narrative Review. Int J Med Students. 2014 MarJun;2(2):64-7. 